\title{
MORPHOMETRIC STUDY OF FORAMEN MAGNUM OF SKULL IN POPULATION OF UTTAR PRADESH
}

\author{
Abhinav Kumar Mishra ${ }^{* 1}$, Shashi Bhushan Pandey ${ }^{2}$, Chandan Kumar Yadav ${ }^{3}$, \\ Mahboobul Haque ${ }^{4}$, Naresh Chandra ${ }^{5}$. \\ *1,3,5 Department of Anatomy, Hind Institute of Medical Sciences, Barabanki, India. \\ ${ }^{2}$ Department of Anatomy, Mayo Institute of Medical Sciences, Barabanki, India. \\ ${ }^{4}$ Department of Anatomy, Integral Institute of Medical Sciences, Lucknow, India.

\section{ABSTRACT}

Background: Foramen Magnum (FM) is a latin word meaning the largest aperture in the base of the skull. It is oval and wider behind, with the greatest diameter $(\mathrm{dm})$ being antero-posterior (AP). The major vital neuroanatomic passes through this largest foramen. Many authors have classified FM depending upon its shapes.

Objectives: To determine the morphometric parameters of Foramen Magnum

Materials and Methods: The study was conducted on 71 dry human skulls of unknown sex and measured its Antero-Posterior, Transverse, Right Oblique and Left Oblique diameters with the help of digital caliper.

Result: The dormancy of Oval shaped Foramen Magnum was found in this study. The range of Antero-posterior and Transverse diameter falls between $30.22-40.9 \mathrm{~mm}$ and 22.67-33.36 mm respectively. The range of Right oblique and Left Oblique diameter was found in between 20.84-35.52 mm and 28.88-35.47 mm respectively.

Conclusion: The present study will useful not only for anatomists but also in neurosurgery. As the nomenclature of the opening in the occipital bone at the base of the skull and bounded by Oval and Rounded on visualization supported by Antero-Posterior and Transverse diameter of the opening.

KEY WORDS: Right Oblique diameter, Left Oblique diameter, Neuroanatomic structures, Foramen Magnum Index.

Address for Correspondence: Dr. Abhinav Kumar Mishra, Department of Anatomy, Hind Institute of Medical Sciences, Barabanki, India. E-Mail : abhinavanatomy07@gmail.com

Access this Article online

Quick Response code

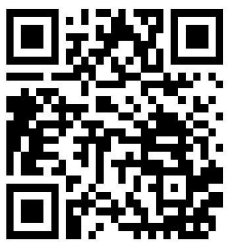

DOI: $10.16965 /$ ijar.2018.150
Journal Information

International Journal of Anatomy and Research

ICV for 2016 ISSN (E) 2321-4287 | ISSN (P) 2321-8967

https://www.ijmhr.org/ijar.htm

DOI-Prefix: https://dx.doi.org/10.16965/ijar

Article Information

Received: 16 Feb 2018

Accepted: 05 Apr 2018

Peer Review: 16 Feb 2018

Published (0): 05 May 2018

Revised: None

\section{INTRODUCTION}

As early as the mid $18^{\text {th }}$ century, it was demonstrated that humans have more anteriorly positioned foramina magna than Chimpanzees, Gorillas, Orangutans, Gibbons and an unspecified array of Guenons, Langurs and Papionins [1]. The base of the skull is formed by the fusion of prechondral chondrocranium and chordal chondrium which ossify by endochondral ossification [2]. Foramen Magnum (FM) is a latin word meaning the largest aperture in the base of the skull [3]. FM lies one third in front and two third behind the line formed by joining the tips of mastoid process [4]. It is oval and wider behind, with the greatest diameter $(\mathrm{dm})$ being anteroposterior (AP) [3]. On each side its anterolateral margin is encroached by Occipital Condyle $(\mathrm{OC})$, hence the FM is narrow anteriorly and the posterior half of the FM is thin and semicircular [5]. The FM is normally about $3 \mathrm{~cm}$ wide and $3.5 \mathrm{~cm}$ AP $[5,6]$. The major vital neuroanatomic structures [7] passes through this largest foramen are medulla oblongata with the meninges, vertebral arteries, anterior spinal 
artery, posterior spinal arteries and accessory spinal nerves. The apical ligament of dens and the tectorial membrane attach to the internal basiocciput [3].

Many authors have classified FM depending upon its shapes such as oval, round, egg, tetragonal, pentagonal, hexagonal and irregu$\operatorname{lar}[8,9]$.

The dimensions like Antero-Posterior Diameter (APD) and Transverse Diameter (TD) are useful in sex determination [10]. Narrowing as well as widening of FM is very important because the dimensions of FM is small in all individuals with achondroplasia [11]. The largest APD permits greater contralateral surgical exposure for condylar resection in transcondylar approach [12] and larger TD permits greater degree of cerebellar tonsillar herniation $[13,14,15,16]$.

\section{MATERIALS AND METHODS}

The study was carried out on 71 completely ossified dry human skulls obtained from Department of Anatomy, Integral Institute of Medical Sciences \& Research and King George's Medical University, Lucknow. The sampling technique used for collection of data was Simple Random Sampling and performed the observational type of study design. Partially or Un-ossified skulls and damaged or deformed skulls were excluded from the study. The parameters were observed twice in this study. All the measurements of Foramen Magnum were taken by Digital caliper.

The Antero-posterior diameter was measured between Basion and Opisthion. (Fig. 3) and the Transverse diameter was measured between the lateral margins of the Foramen Magnum at the point of greatest lateral curvature. (Fig. 4)

Right and Left Oblique diameter was measured from the midpoint of the tip of the tubercle of the corresponding occipital condyle to the midpoint of the posterior ends of opposite condyle and Opisthion. (Fig. 5 \& Fig. 6)
Fig. 2: Comparison of Shape of FM with Previous Studies.

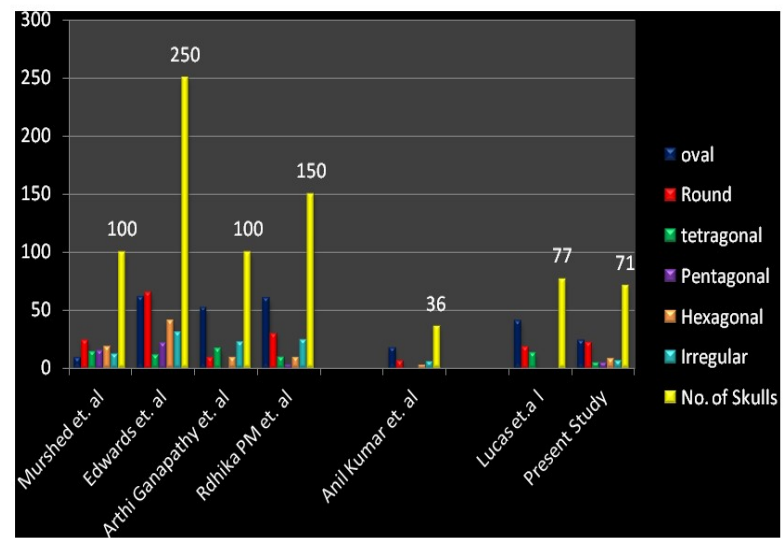

Fig. 3: Measurement of Antero-Posterior Diameter.

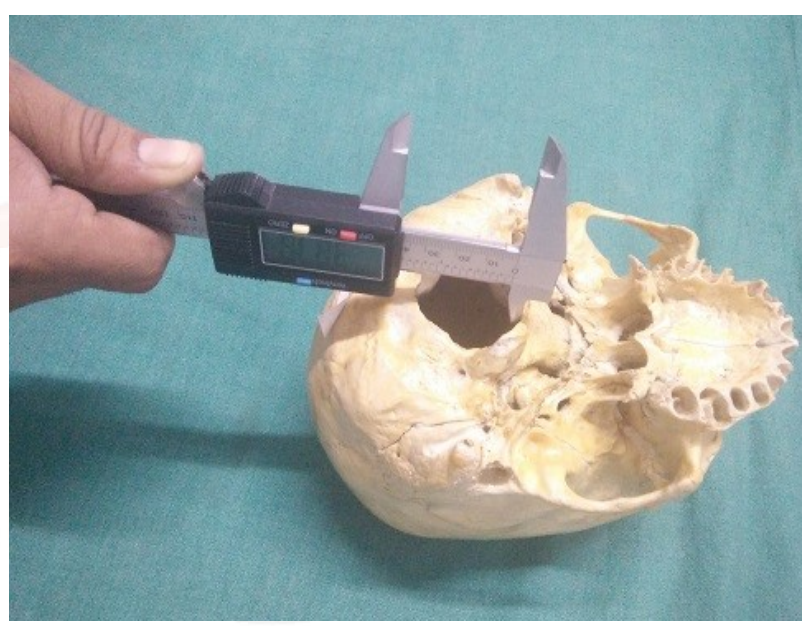

Fig. 4: Measurement of Transverse Diameter.

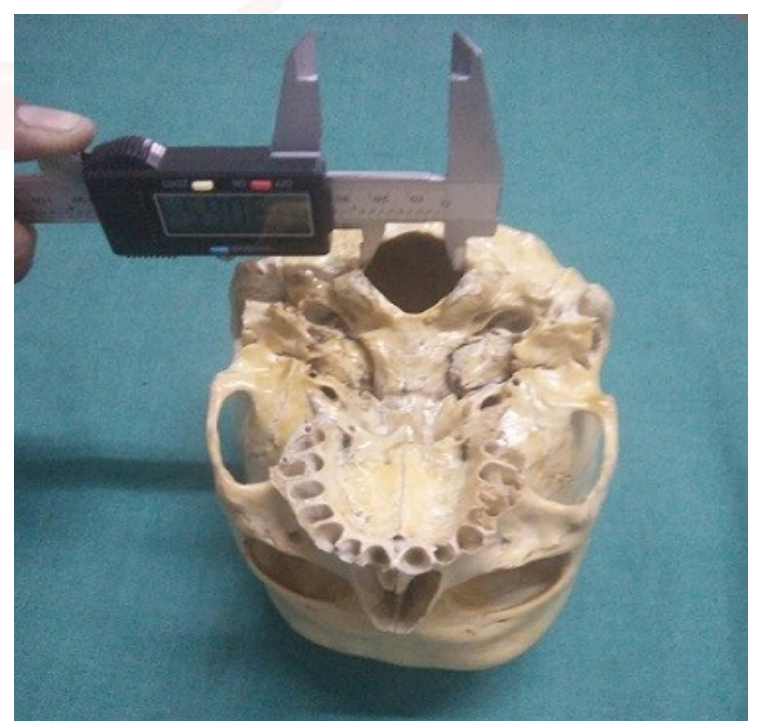

Fig.1: Showing different types of shapes of Foramen Magnum.

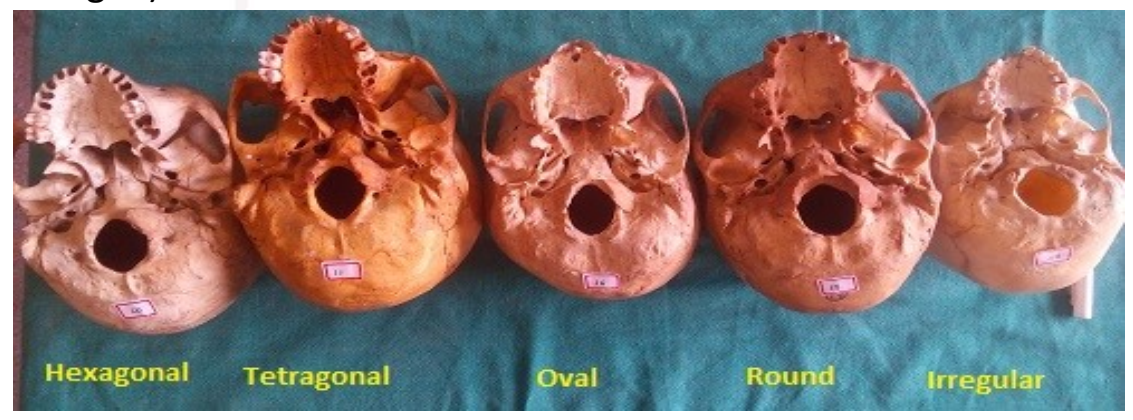


Fig. 5: Measurement of Right Oblique Diameter.

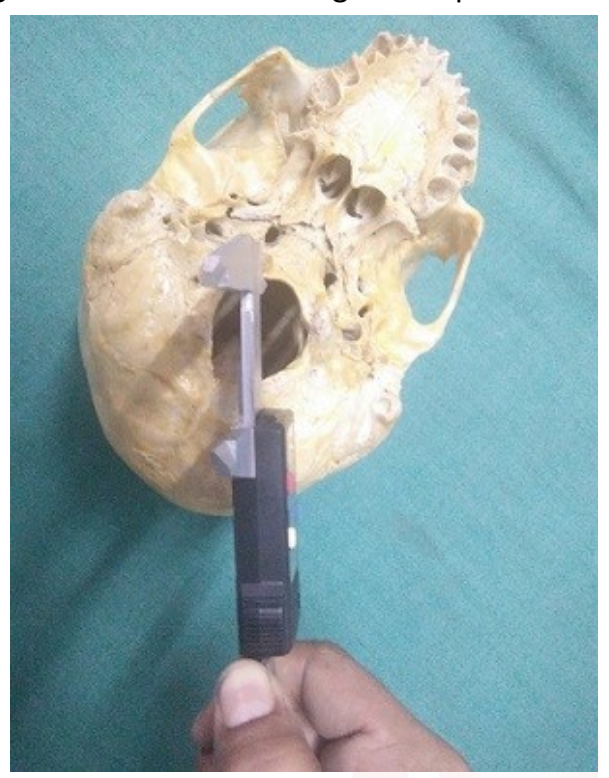

Fig. 6: Measurement of Left Oblique Diameter.

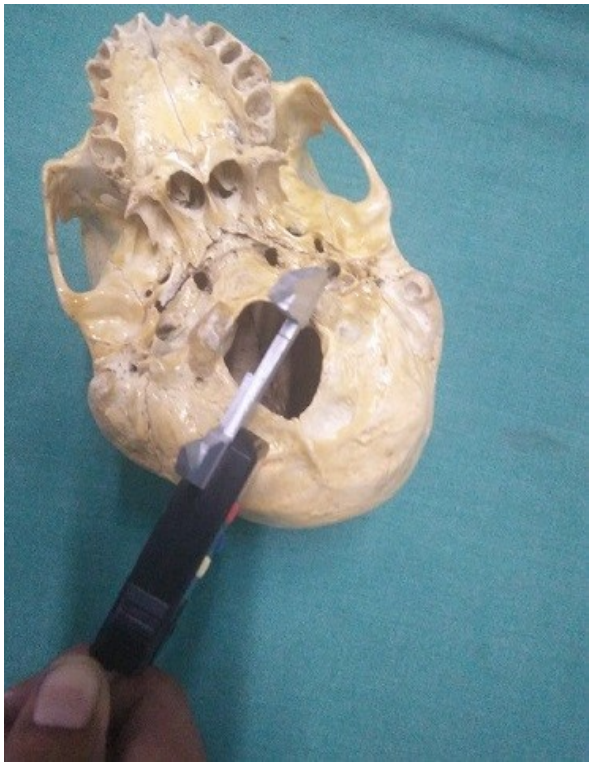

Table 1: Comparison of Shape of FM with Previous Studies.

\begin{tabular}{|c|c|c|c|c|c|c|c|c|}
\hline \multirow[b]{2}{*}{ S. No. } & \multirow[b]{2}{*}{ Author } & \multicolumn{6}{|c|}{ Types of Shapes of Foramen Magnum } & \multirow[b]{2}{*}{$\begin{array}{l}\text { Total No. } \\
\text { of Skulls }\end{array}$} \\
\hline & & $\begin{array}{c}\text { Oval } \\
\text { No. (\%) }\end{array}$ & $\begin{array}{l}\text { Round } \\
\text { No. (\%) }\end{array}$ & $\begin{array}{c}\text { Tetragonal } \\
\text { No. (\%) }\end{array}$ & $\begin{array}{c}\text { Pentagonal } \\
\text { No. (\%) }\end{array}$ & $\begin{array}{c}\text { Hexagonal } \\
\text { No. (\%) }\end{array}$ & $\begin{array}{l}\text { Irregular } \\
\text { No. (\%) }\end{array}$ & \\
\hline 1 & Murshed et. al & $9(8.1)$ & $24(21.8)$ & $14(12.7)$ & $15(13.6)$ & $19(17.2)$ & $12(10.9)$ & 100 \\
\hline 2 & Edwards et. al & $61(24.4)$ & $65(26)$ & $11(4.4)$ & $21(8.4)$ & $41(16.4)$ & $31(12.4)$ & 250 \\
\hline 3 & Arthi Ganapathy et. al & 52 & 9 & 17 & - & 9 & 22 & 100 \\
\hline 4 & Radhika PM et. al & $60(40)$ & $30(20)$ & $9(6)$ & $3(2)$ & $9(6)$ & $24(16)$ & 150 \\
\hline 5 & Anil Kumar et. al & $18(50)$ & $7(20)$ & $2(6)$ & - & $3(8)$ & $6(16)$ & 36 \\
\hline 6 & Lucas et. al & $41(53.24)$ & $19(24.67)$ & $13(16.88)$ & $1(1.29)$ & $1(1.29)$ & - & 77 \\
\hline 7 & Present Study & $24(37.8)$ & $22(30.9)$ & $5(7.04)$ & $5(7.04)$ & $8(11.2)$ & $7(9.85)$ & 71 \\
\hline
\end{tabular}

Table 2: Comparison of APD \& TD Dimensions with previous studies.

\begin{tabular}{|c|c|c|c|c|}
\hline S.No. & Authors & Area & $\begin{array}{c}\text { APD } \\
(\mathrm{mm})\end{array}$ & $\begin{array}{c}\text { TD } \\
(\mathrm{mm})\end{array}$ \\
\hline 1 & Murshed et. al & Turkey & 35.9 & 30.45 \\
\hline 2 & Edwards et. al & Switzerland & 30 & 24 \\
\hline 3 & Gagandeep Singh et. al & Punjab & 33.54 & 27.77 \\
\hline 4 & Arthy Ganapathy et. al & Pondicherry & 33.9 & 28.7 \\
\hline 5 & Radhika P.M. et. al & Bangalore & 35.3 & 29.4 \\
\hline 6 & Anil Kumar et. al & Oman & 36.78 & 30.05 \\
\hline 7 & Lucas et. al & Brazil & 34.23 & 28.62 \\
\hline 8 & Present Study & Uttar Pradesh & $\mathbf{3 4 . 0 9}$ & $\mathbf{2 8 . 2 2}$ \\
\hline
\end{tabular}

Table 3: Antero-Posterior and Transverse Diameters of FM.

\begin{tabular}{|c|c|c|c|c|}
\hline $\begin{array}{c}\text { No. of } \\
\text { Samples }\end{array}$ & Parameters & Min-Max (mm) & Mean \pm SD & $p$-Value \\
\hline \multirow{2}{*}{71} & APD & $30.22-40.9$ & $34.09 \pm 2.23$ & \multirow{2}{*}{$<0.0001$} \\
\cline { 2 - 4 } & TD & $22.67-33.36$ & $28.22 \pm 2.19$ & \\
\hline
\end{tabular}

Table 4: Parameters of Right Oblique and Left Oblique Diameters.

\begin{tabular}{|c|c|c|c|c|}
\hline $\begin{array}{c}\text { No. of } \\
\text { Samples }\end{array}$ & Variables & $\begin{array}{c}\text { Min - Max } \\
(\mathrm{mm})\end{array}$ & Mean \pm SD & p-Value \\
\hline \multirow{2}{*}{71} & ROD & $20.84-35.52$ & $28.67 \pm 2.26$ & \multirow{2}{*}{$=0.5931$} \\
\cline { 2 - 4 } & LOD & $28.88-35.47$ & $28.88 \pm 2.35$ & \\
\hline
\end{tabular}

Fig. 7: Comparison of ROD \& LOD with previous studies.

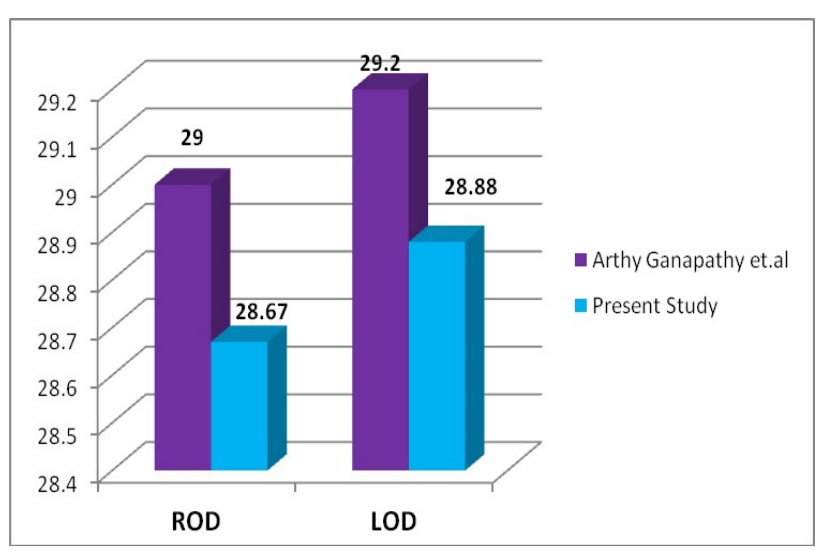




\section{RESULTS}

The types of shapes distribution of Foramen Magnum found as Oval type $33.80 \%$, Round $30.98 \%$, Tetragonal 7.04\%, Pentagonal 7.04\%, Hexagonal $11.26 \%$ and Irregular were $9.85 \%$. The parametric distribution of APD and TD in which the mean \pm SD of APD is $34.09 \pm 2.23$ and the mean \pm SD of TD is $28.22 \pm 2.19$ whereas it lies in the range between min-max are 30.224.09 in APD and 22.67-33.36 in TD respectively. There is a positive correlation found between APD and TD at $p<0.05$ level of significance (Table.3) and the parametric distribution of ROD and LOD in which the mean \pm SD of ROD is 28.67 \pm 2.26 and the mean \pm SD of LOD is $28.88 \pm 2.35$ whereas it lies in the range between min-max is 20.84-35.52 in ROD and 24.29-35.47 in LOD respectively. There is no correlation found between ROD and LOD which is statistically not significant at $p<0.05$ level of significance (Table. 4 \& Fig. 7).

\section{DISCUSSION}

Foramen Magnum is a large foramen in Occipital bone of skull and it contains several critical neuroanatomical and vascular structures of which the surgeon has to aware [17]. Various authors has reported variation in different morphological parameter of FM out of which shape seems to be most important have got diagnostic, clinical and radiological importance [18]. The irregular shape of FM is accentuated by the developmental anomalies of the bone [19]. The present study provides valuable data pertaining to the FM. In this study effort has been made to find the parameters of FM.

In the present study dominant type of shape of FM was Oval type $(n=24)$ which was similar to study done by Arthy Ganapathy et al. in 52 skull in Pondicherry region. The same predominance of Oval shape FM was also found by Radhika P.M. et al. in Bangalore region, Anil Kumar et al. in Oman region and Lucas et al. in Brazil population. Whereas Murshed et al. and Edwards et al. found the Round Shape FM dominancy in their study. The results of different studies regarding shape of FM is done in Table-1 and shown by bar diagram in Fig 2.

In the present study the mean of APD was 34.09 which was similar to the study done by Gagandeep Singh et al. in Punjab region. The same parameter was also found by Arthy Ganapathy et al. in Pondicherry region, Radhika PM et al. is in Bangalore region and Lucas et al. in Brazil region. A study done by Edwards et al. in Switzerland region was less frequent whereas Murshed et al. in Turkish region and Anil Kumar et al. in Oman region found slightly more mean of APD than present study. In the present study the mean of TD was 28.22 which were similar to the study done by Gagandeep Singh et al. in Punjab region. The same parameter of TD was also found by Arthy Ganapathy et al. in Pondicherry region, Radhika PM et al. in Bangalore region and Lucas et al. in Brazil population. The mean of TD in present study was found lower than the study conducted by Murshed et al. in Turkish region and Anil Kumar et al. in Oman region. But the mean of TD in the present study was found higher than a study done by Edwards et al. in Switzerland population.

The results of different studies regarding of FM is APD and TD is compared on Table- 2 In the present study the mean of ROD and LOD found similar to the study conducted by Arthy Ganapathy et al. in Pondicherry region. If any other variations will found it will be considered and compared. The results of study regarding ROD and LOD of FM are shown by bar diagram in Fig. 7.

\section{CONCLUSION}

The present study concludes that the Nomenclature of the opening in the occipital bone at the base of the skull as a Foramen Magnum is appropriate as the shape appear to the Oval and Rounded on visualization supported by the Antero-Posterior and Transverse Diameter of the opening, the Shape of the Foramen Magnum corresponds to the shape of the Spinal Cord and also helpful in the Stature.

\section{Conflicts of Interests: None}

\section{REFERENCES}

[1]. Dubebenton. Memoire surles differences de la situation du grand from occipital dans I'hamme et. dens les animaux. Mem. Acad. Sci.1764;66:568-575.

[2]. Sadler T.W. Langman's Medical Embryology. Philadelphia : Wolter Kluwer, 2012;10:133-136. 
[3]. Standring S, Gray's Anatomy: The Anatomical Basis of Clinical practice. 39th edition. Edinburg: Elsevier Churchill Livingstone, 2005;463-465.

[4]. Sinnatamby C.S. Last's Anatomy regional and applied. $10^{\text {th }}$ edition. Churchill Livingstone, 1999;561571.

[5]. Oliveira Ed., Rhoton AL, Peace D. Microsurgical anatomy of the region of the foramen magnum. Surg. Neurol. 1985;24:293-352.

[6]. http//en.wikipedia.org/wiki/foramen_magnum accessed on $18^{\text {th }}$ July 2009.

[7]. Snell R.S. Clinical Anatomy for Medical Student. $4^{\text {th }}$ edition. Boston; Little, Brown and Company: 1992:808-812.

[8]. Zadvornovlu N. Variations in the shape of the foramen magnum and the structure of its posterior border. Arkh. Anat. Gistol. Embriol., 1972;63(7):42-50.

[9]. Zaidi S.H., Dayal S.S. Variations in the shape of foramen magnum in Indian skulls. Anat. Anz. Jena. 1988;167:338-40.

[10]. Gunay Y., Altinkök M. The value of the size of foramen magnum in sex determination. J. Clin. Forensic Med. 2000;7:147-149.

[11]. Hetch T.J., Horton W.A., Reid C.S., Pyeritz R.E., Chakraborty R. Growth of the foramen magnum in acondroplasia. American J. Med. Gen. 1989;32:528535.

[12]. Muthukumar N., Swaminathan R., Venkatesh G., Bhamumathi S.P. A morphometric analysis of the foramen magnum region as it relates to transcondylar approach. Acta. Neurochir. (Wien). 2005;147(8):889- 895.

[13]. Taghipour M., Moin H., Zamanizadeh B., Kamkarpour A. and Esmaeeli M. Foramen Magnum Surgery: Experience With 22 Cases. Neurosurgery Quarterly. 2006 ; 16: 96-99.
[14]. Rhoton A.L. The Far-Lateral Approach and Its Tanscondylar, Supracondylar, and Paracondylar Extensions. Neurosurgery. 2000;47(3):S195-S209.

[15]. Rhoton A.L. The Foramen Magnum. Neurosurgery. 2000;47(3):S155-S194.

[16]. Kawashima M., Tunriover N. and Rhoton A.L. Comparasion of The Far Lateral And Extreme Lateral Variants of The Atlanto-Occipital Transarticular Approach To Anterior-Extradural Lesions Of The Craniovertebral Junction. Neurosurgery. 2003;53:662-675.

[17]. Boutaon M.R., Cusimano M.D. Foramen magnum meningiomas : Concepts, classifications, and Naunces. Neurosurg Focus. 2003 ;14:e.10.

[18]. Murshed Khalil Awadh, Cicekibasi Emine Aynur, Tuncer Isik. Morphometric Evaluation Of The Foramen Magnum And Variations In Its Shape: A Study on Computerized Tomographic Images of Normal Adults. Turk. J. Med. Sci. 2003;33:301-306.

[19].Furtado Sunil V. , Thakre Darpan J. , Venkatesh Prasanna K., Reddy Kalyan, Hegde A. S. Morphometric Analysis Of Foramen Magnum Dimensions And Intracranial Volume In Pediatric Chiari-1 Malformation. Acta. Neurochirurgica. 2010;152(2):221227.

How to cite this article:

Abhinav Kumar Mishra, Shashi Bhushan Pandey, Chandan Kumar Yadav, Mahboobul Haque, Naresh Chandra. MORPHOMETRIC STUDY OF FORAMEN MAGNUM OF SKULL IN POPULATION OF UTTAR PRADESH. Int J Anat Res 2018;6(2.2):5186-5190. DOI: 10.16965/ijar.2018.150 